\title{
HIRUDINEA AS HUMAN PARASITES IN PALESTINE.
}

\author{
By E. W. G. MASTERMaN, F.R.C.S., D.P.H. Camb.
}

LEECHES are common in the fountains and pools of Palestine, particularly in the northern parts, known to us familiarly as 'Galilee,' and further north in the district of the Lebanon. In the later summer and autumn months they are so plentiful in places that almost every horse and mule passing through these parts bas a bleeding mouth. Under such conditions it is not wonderful that human beings from time to time are attacked. The domestic supplies of water are usually protected by the water-carrier's custom of straining it through a piece of fine muslin as he or she fills the pitcher. In some parts of the land the water at the source is kept free from leeches by means of fish; at Deishun, for example, a village in 'Upper Galilee' inhabited by Algerian settlers, the large stone tank into which the spring runs is full of a special fish-Capoëta fratercula, a kind of carp-which is there bred for the purpose and which is treasured by the inhabitants with superstitious reverence. Many of the springs in the mountains of Galilee and in the Lebanon are widely known for the multitude of leeches which lurk in their waters, but a thirsty traveller seldom has self-control enough to restrain himself from drinking, and when he does so, particularly at dusk or in the night, he is very likely to suck one in. It is stated in Allbutt and Rolleston's System of Medicine (2nd ed. Vol. II. Part II. p. 959) that the leech "remains in the stomach for a time and then begins to wander." I have had a long experience of leeches as human parasites but have never seen nor heard of a case like this. The leech in every case I have met has attached itself to the mouth, throat, etc. in the process of swallowing, and I am convinced that once the leech reaches the stomach it is killed. I have never heard of any after symptoms from cases where to my knowledge a leech has been completely swallowed. Many patients can describe the actual moment 
(during deglutition) when the leech seizes on the throat. One would suppose from the great frequency of leeches in the mouths of horses, etc., that they must sometimes find a temporary resting place there in the human subject; such cases do not however come into the hands of a medical man-the patient or his friends readily removes such an intruder. In the cases, some three dozen or so, which I bave had under my own observation the leech has been attached to the epiglottis, the pharynx, the nasal cavities, or-most common of all-the larynx. The frequency of the last situation in my clinical experience is doubtless due to the inability of the fellahin to do anything themselves for the relief of such cases.

The characteristic symptom produced by Hirudinea is the occurrence of constant small haemorrhages from the mouth or nose. Last summer in Safed I had a baby of about seven months brought to me with a history of almost continuous slight epistaxis from the left nostril of a week's duration. The child had been brought a considerable distance for treatment. On examining the nostril I noticed something blackish a little way up, and introducing a pair of fine sinus forceps I had the satisfaction of drawing out a slender leech about $1 \frac{1}{2}$ ins. long. The symptoms were at once relieved. The first case I had, on September 16, 1893 , also at Safed, was remarkable. The patient, a girl of 12 , came complaining of constant small haemorrhages from the mouth for three days; there was no dyspnoea nor aphonia. I put my right index finger well to the back of the tongue to see if I could feel anything abnormal in the neighbourhood of the epiglottis, and when I drew it forth was astonished to find a small leech looped up upon my finger-nail. These are mild cases. When the leech lies deeper the symptoms are much more distressing. The haemorrhage, though never great in quantity at any one time, may, when prolonged, be very serious and even fatal. I know of two eases where the patient actually died from this. One, which occurred shortly before I came to Palestine, was narrated to me by Dr Torrance of Tiberias. The man came under medical treatment already reduced to extreme anaemia by prolonged haemorrbage; all efforts failed to reach the leech and it was only after complete eversion of the patient that it was at last extruded, but the patient nerer recovered the loss of blood. The second case is that of a young fellah girl who was brought to Safed last summer for the removal of a leech which she had harboured in her throat for some weeks. She just reached Safed before she died as a result of anaemia.

The haemorrhagic discharge is pure blood, bright in colour and, 
when the leech is in the pharynx or larynx, it is 'hawked up' almost continuously. As a rule, and of course in all laryngeal cases, there is considerable irritation about the larynx resulting in a short irritating cough, dyspnoea, varying in intensity from time to time, and sometimes considerable cyanosis from impeded respiration. The patient's expression is one of considerable distress, a great contrast to that following upon the instant relief afforded by the removal of the parasite. In laryngeal cases there is often complete loss of voice, the patient only speaking in a whisper and then with difficulty. On examination with a tongue depressor the leech is sometimes revealed, lying at the back of the pharynx ; in such a situation it cannot be mistaken as its black, rounded, annulated, shiny outline at once catches the eye. More commonly it is necessary to use the laryngoscope, and in a considerable proportion of cases the leech will be found attached close to one of the vocal cords. Its head attachment is sometimes just inside or just outside the cord, and it flops in and out of the aperture with the respiration. In such cases the wonder is not that the patient suffers from dyspnoea, but that he can breath at all. The upper larynx and the pharynx are largely bespattered with fresh blood and in the process of examination the patient usually coughs out a good deal of it. Why it is that a leech, which outside the body takes its fill and then drops off or is easily removed, continues when inside the mouth and throat to keep its hold, though apparently attacking different spots-leaving the old points to bleed-is a question I must leave to zoologists, but it is certainly the case, and in my experience in such a situation it seldom voluntarily quits its hold. According to the System of Medicine quoted above this species of Hirudinea is Limnatis nilotica.

As regards the treatment, the natives of Palestine are accustomed if the worm is within their reach to transfix it with a sharp thorn from the Sidr tree: I have seen muleteers use a packing needle to extract a leech from a mule's mouth. When the parasite is beyond reach of this process they use what they call es salata, that is the thick deposit which collects in their tobacco pipes. This they smear on the end of a fragment of wood and they say that if this touches the leech it is poisoned and leaves its bold. The cases which came to the European practitioner are almost always those where the skill of the amateur has failed and for these such simple means are useless. In my experience too the 'spraying with salt solution' mentioned in Allbutt and Rolleston's System has proved of little use. The two means I have found most successful are either mechanically seizing the worm by means of suitable forceps or paralysing it with cocaine. 
In a certain proportion of cases it is possible to seize the leech. With pharyngeal cases this should be the rule and perbaps with throat specialists it might also be the case with laryngeal cases. For the ordinary surgeon, though it is simple enough to watch the worm through laryngoscope mirror, it is very difficult to seize the writhing, slippery creature amidst the spasmodic contractions of the larynx and the frequent coughing. Spraying with cocaine is a great help, but I must admit that in mechanically removing the leech $I$ have several times had failures. The second method, which $I$ have never yet known to fail, I owe to the suggestion of Dr Mackinnon of Damascus-this is the application of a strong solution of cocaine to the parasite. It is not enough to spray in cocaine or paint it indiscriminately. For sure success a small pledget of cotton-wool, saturated with a $30 \%$ cocaine solution, should be actually brought in contact with the parasite by carefully directed movements guided by the help of the laryngoscopic mirror. The strong cocaine solution, if it reaches the surface of the leech undiluted al ways produces in a few minutes-not, in my experience, instantaneously -a paralysing effect, causing it to relinquish its hold. My last three cases, all treated in this way, were speedily successful. In the case of one of these patients the man apparently swallowed the leech for he had no more symptoms from a few minutes after treatment; in the second case the leech was suddenly coughed into the mouth about five minutes after the cocaine application and I removed it from the mouth with my finger. The last case was one I found in our Hospital in Jerusalem immediately on my return from Safed. The man had for nearly a week been 'spitting blood,' and when I was called to see him a spittoon full of practically pure blood was lying on the locker by his side and every few minutes he was adding more: his lips were cyanosed; he was unable to speak above a whisper and every few seconds he had a short cough. I sprayed cocaine solution upon the fauces and the laryngeal mirror at once revealed a large leech attached close to one of the vocal cords. After several vain efforts to seize it with curved forceps I applied cocaine as described and then made the man lie prone upon his bed with his head hanging over the edge. After a few minutes he coughed up the leech on to the floor. I have heard it stated that there is a danger that the parasite on leaving its hold may fall downwards and lodge on one of the bronchi, then die and set up septic changes. I have never seen such a case, but such a danger is doubtless obviated by making the patient assume the position I have described when the cocaine is commencing to have its effect. 